\title{
Ibrutinib-Associated Atrial Fibrillation: A Practical Approach
}

López-Fernández $\mathrm{T}^{1 *}$, Canales $\mathrm{M}^{2}$, Farmakis $\mathrm{D}^{3}$, García-Sanz $R^{4}$, Bosch F $^{5}$, Loscertales J ${ }^{6}$, Rivas Pollmar $\mathrm{MI}^{7}$, Abad-Santos $\mathrm{F}^{8}$, Anguita $\mathrm{M}^{9}$ and Zamorano J L ${ }^{10}$

${ }^{1}$ Cardio-Oncology Unit, Cardiac Imaging Unit, Department of Cardiology, University Hospital La Paz, IdiPAZ Research Institute, Spain

${ }^{2}$ Cardio-Oncology Unit, Department of Hematology, University Hospital La Paz, IdiPAZ Research Institute, Spain

${ }^{3}$ Cardio-Oncology Clinic, Heart Failure Unit, Department of Cardiology, University Hospital Attikon, National and Kapodistrian University of Athens Medical School, Athens, Greece; European University Cyprus Medical School, Spain

${ }^{4}$ Department of Hematology, University Hospital

Salamanca, Salamanca, Spain

${ }^{5}$ Department of Hematology, University Hospital

Valld'Hebron, VHIO, Spain

${ }^{6}$ Department of Hematology, Hospital Universitario de La Princesa, IIS-IP, Spain

${ }^{7}$ Department of Hematology, University Hospital La Paz, IdiPAZ Research Institute, Spain

${ }^{8}$ Department of Clinical Pharmacology, Hospital

Universitario de la Princesa, Instituto de Investigación

Sanitaria la Princesa (IP), Spain

${ }^{9}$ Department of Cardiology, University Hospital Reina

Sofia, Córdoba, Spain

${ }^{10}$ Department of Cardiology, University Hospital Ramon

YCajal, Spain

*Corresponding author: Lopez Fernandez T,

Department of Cardiology, La Paz University Hospital, Department of Cardiology, La Paz University Hospital Paseo de la Castellana 261, 28046, Madrid, Spain

Received: April 16, 2018; Accepted: May 07, 2018;

Published: May 22, 2018

\begin{abstract}
Over the past decades there has been a significant reduction in cancer-related mortality thanks to the advances in screening, early detection, and treatment. Despite that, there is a growing awareness of the potential cardiovascular side effects of both traditional and novel anticancer drugs. Patients with lymphoid malignancies treated with tyrosine kinase inhibitors are a population with a particularly high cardiovascular risk profile. Ibrutinib, a first-in-class irreversible oral inhibitor of Bruton tyrosine kinase, has proven to be highly effective in chronic lymphocytic leukemia and related B-cell malignancies. However, it is not always optimally administered in clinical practice due to a growing concern of the management of its potential cardiovascular side effects. The present article providesa multidisciplinary and practical approach to the prevention, monitoring and treatment of atrial fibrillation in patients with lymphoid malignancies treated with ibrutinib.
\end{abstract}

Keywords: Ibrutinib; Atrial fibrillation; Chronic lymphocytic leukemia; B-cell malignancies; Cardiotoxicity; Cardio-oncology

\section{Abbreviations}

AF: Atrial Fibrillation; APT: Antiplatelet Therapy; BTK: Bruton Tyrosine Kinase; CLL: Chronic Lymphocytic Leukemia; CV: Cardiovascular; CYP3A4: Cytochrome P450 enzyme 3A4; DAPT: Dual Antiplatelet Therapy; DDI: Drug-drug interactions; ECG: Electrocardiogram; MCL: Mantle Cell Lymphoma; MZL: Marginal Zone Lymphomas; NOACs: Non-vitamin K Antagonist Oral Anticoagulants; P-gp: P-glycoprotein; TEC: Tyrosine Kinases expressed in Hepatocellular Carcinoma; TKI: Tyrosine kinase inhibitors; VKAs: Vitamin K Antagonists; WM: Waldenström macroglobulinemia

\section{Introduction}

In recent decades, cancer survival rates have markedly improved as a result of advances in screening, early detection and anticancer treatments. At the same time, there is a growing awareness of the potentially negative effects of both traditional and novel cancer therapies on the cardiovascular (CV) system $[1,2]$. Thereby, cardiooncology, the multidisciplinary CV care of cancer patients, has been proposed as a new approach to improve prevention, early identification and management of cardiotoxicity [3-5].

In lymphoid malignancies, newer targeted therapies, such as tyrosine kinase inhibitors (TKI) are increasingly been used, leading to new concern son "off-target" effects. Among them, ibrutinib, a firstin-class irreversible oral inhibitor of Bruton tyrosine kinase (BTK) involved in the B-cell receptor signaling pathway, has proven to be effective in chronic lymphocytic leukemia (CLL) and other B-cell malignancies, including mantle cell lymphoma (MCL), Waldenström macroglobulinemia (WM) and marginal zone lymphomas (MZL) [6]. These disorders are usually diagnosed in elderly patients with coexisting medical conditions that may influence the ability to tolerate the treatment and contribute to an increased risk of toxicity 


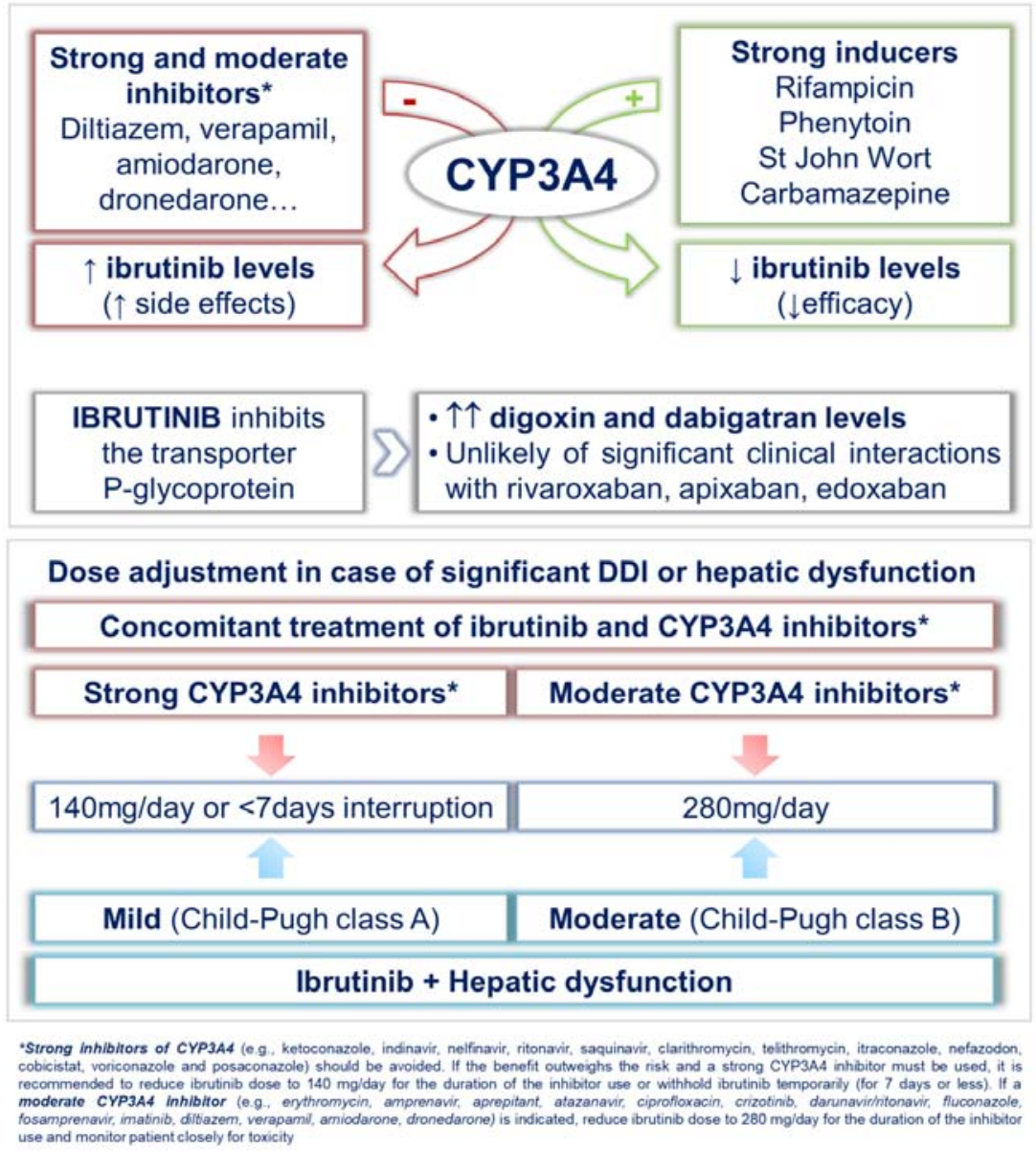

Figure 1: Ibrutinib drug-drug interactions (upper panel) and indicated dose modifications (lower panel) in case of significant interactions or hepatic dysfunction.

[7]. Ibrutinib administration has been associated with an increased risk of bleeding, infections, atrial fibrillation (AF), and hypertension [8]. However, owing to the lack of evidence-based recommendations, managing these side effects is challenging. This is particularly relevant for stroke prevention and bleeding risk stratification in patients with ibrutinib-associated AF.

The present article provides a multidisciplinary hematocardiology practical approach to the prevention, monitoring and treatment of $\mathrm{AF}$ in patients with lymphoid malignancies receiving ibrutinib.

\section{Atrial fibrillation in hematologic malignancies: prevalence and risk factors}

$\mathrm{AF}$ is the most common sustained arrhythmia in the general population [9]. It occurs more frequently in patients with cancer, due to the effects of the tumor and/or the anticancer drugs, combined with the coexistence of several conditions independently associated with AF (Table 1) [9-11]. Treating AF in cancer is a challenge, especially in terms of antithrombotic therapy, because standard risk prediction scores do not consider the increased risk of thrombosis nor hemorrhage in active cancer patients $[3,4,9]$.

Notwithstanding the prevalence of AF in hematologic malignancies remains basically unknown, several retrospective studies have observed an increasing trend in lymphoid malignancies especially associated with the use of anthracycline-based regimens $[3,4,12]$. Recent series in CLL have demonstrated a $6 \%$ prevalence of AF at the time of diagnosis [7], generally related to the high CV risk profile of such patients, as they are predominantly men with a median age at diagnosis of 71 years-old. Other risk factors include hypertension, hyperlipidemia and diabetes, also present in 40\%,39\% and $10 \%$ of CLL patients, respectively [7]. Likewise, a high percentage of prior chronic respiratory diseases (17\%) and cardiac conditions (coronary artery disease, 13\%; valvular heart disease, 5\%) have also been reported in these patients [7]. As in other high risk populations, early identification, management of comorbidities and patient education are essential to reduce adverse events and to increase AFtherapy adherence $[9,13]$.

\section{Atrial fibrillation and ibrutinib: epidemiology}

The incidence rate of AF is substantially higher among ibrutinibtreated patients with B-cell malignancies than in the general population [14,15]. Nevertheless, the implicate pathophysiology is not yet elucidated. It has been postulated that ibrutinib may have an inhibitory effect of BTK and tyrosine kinases expressed in hepatocellular carcinoma (TEC), expressed in human myocytes, leading to decrease of the PI3K-Akt cardio-protective pathway, although this has not been confirmed and other theories suggest that 


\section{A. Patients with pre-existing atrial fibrillation}

\begin{tabular}{|c|c|c|}
\hline & $\begin{array}{l}1^{\text {st }} \text { option } \\
\beta \text {-blockers }\end{array}$ & \\
\hline \multirow[t]{2}{*}{$\begin{array}{l}\text { Permanent/Persistent AF } \\
\text { Rate control therapy } \\
\text { (resting heart rate } 60-100 \mathrm{bpm} \text { ) }\end{array}$} & $\begin{array}{c}\text { Caution } \\
\text { Amiodarone, digoxin }\end{array}$ & \\
\hline & $\begin{array}{c}\text { Avoid } \\
\text { Verapamil, diltiazem }\end{array}$ & \\
\hline \multirow{2}{*}{$\begin{array}{c}\text { Paroxysmal AF } \\
\text { (self terminating or }<7 \text { days) } \\
\text { - Maintain antiarrhythmic drugs } \\
\text { - Review drug-drug interactions }\end{array}$} & $\begin{array}{l}\text { New AF event in } \\
\text { patients without RFA }\end{array}$ & $\begin{array}{l}\text { Adjust antiarrhythmic } \\
\text { drugs }+/ \text { - } \beta \text {-blockers }\end{array}$ \\
\hline & $\begin{array}{l}\text { New AF event in } \\
\text { patients with RF⿳ }\end{array}$ & $\begin{array}{c}\text { Prioritize rate control } \\
\text { therapy }\end{array}$ \\
\hline
\end{tabular}

$\triangle \mathrm{RF}=$ Atrial fibrillation risk factors: $>65$ years-old, men, obesity, diabetes, hyperthyroidism, moderate to severe chronic obstructive lung disease, heart failure, moderate to severe valvular heart disease

\section{B. Incident atrial fibrillation under ibrutinib}

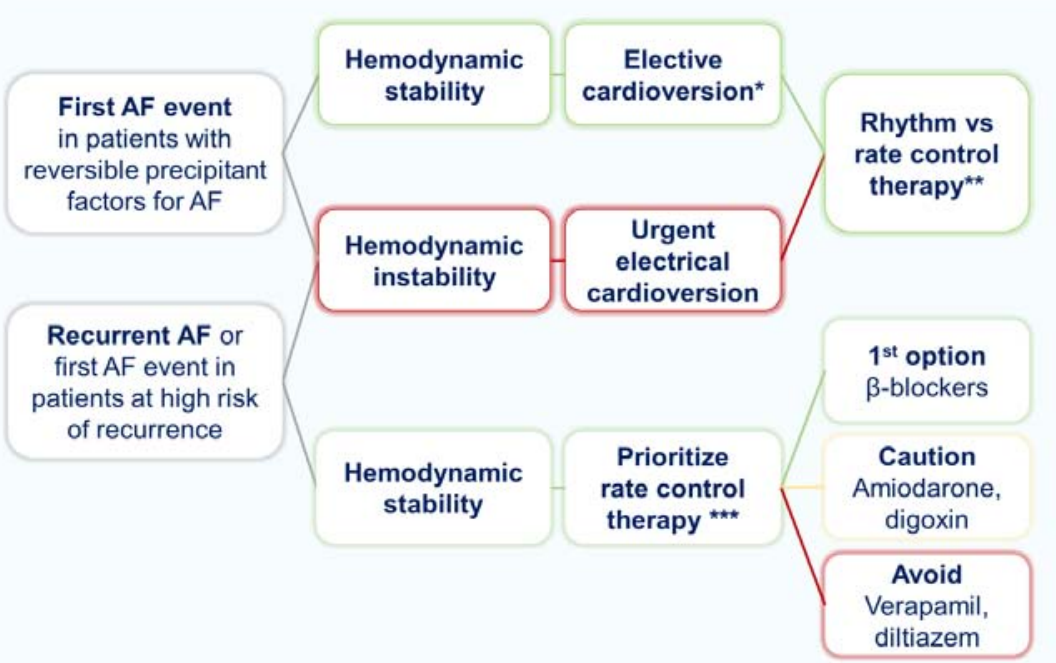

Figure 2: Management of patient with pre-existing $(A)$ or incident $(B)$ atrial fibrillationon ibrutinib therapy.

AF: Atrial Fibrillation; bpm: beats per minute

*Pharmacological cardioversion (flecainide or vernakalant) is preferred in patients without significant structural heart disease (heart failure, severe aortic stenosis, acute myocardial infarction) and AF lasting $<24$ hours, while electrical cardioversion is more effective in patients with AF lasting $>24$ hours.

Before elective cardioversion is mandatory to optimize anticoagulation therapy based on $\mathrm{CHA}_{2} \mathrm{DS}_{2} \mathrm{VASc}$ score. If AF $\leq 48$ hours optimize anticoagulation and proceed with cardioversion. If AF> 48 hours a 4 weeks period of anticoagulation or a previous transesophageal echocardiography (to rule out intracardiac thrombus) is needed.

${ }^{*}$ Rhythm control therapy is recommended to improve symptoms controlin patient without or minimal structural heart disease (prioritize flecainide or propafenone +/- beta-blockers). Amiodarone and dronedarone should be used with caution due to DDI. Rate control therapy is prioritized in patients with coronary artery disease, significant valvular heart disease or heart failure. AF catheter ablation should be based on a Cardio-Hematology Team recommendation in selected patients.

${ }^{* * * *}$ Initial resting heart rate target $<110 \mathrm{bpm}$ (stricter if persistent heart failure or AF symptoms). Long-term resting heart rate target $60-100 \mathrm{bpm}$.

AF may be an off-target effect of the drug [14].

The risk of $\mathrm{AF}$ is the highest in the first months of ibrutinib therapy, with a median time of onset of 6-14 months, however the incidence increases over time [16]. The estimated cumulative incidence in CLL patients increases from $5.9 \%$ at 6 months to $16 \%$ by 28 months $[16,17]$. Most AF events observed in ibrutinib-treated patients were grade $2(85.5 \%)$ [17]. Similarly, in WM patients, the cumulative incidence at one, two, and three years was $5.4 \%, 7.1 \%$, and $8.9 \%$, respectively [18]. In MCL, the 2-year cumulative incidence was $14.2 \%$ [19].

Ibrutinib-associated AF occurs earlier in patients with past history of AF (median time after the onset of ibrutinib of 2.2 months) than in patients with incident $\mathrm{AF}$ (median time of 10.9 months) [17]. Therefore, patients with prior history of AF and those aged over 65, with suboptimal blood pressure control, diabetes, heart failure or valvular heart diseases are at the highest risk for developing AF when 


\section{Anticoagulation management based on $\mathrm{CHA}_{2} \mathrm{DS}_{2} \mathrm{VASc}$ score}

First option in non-valvular AF*: apixaban, edoxaban or rivaroxaban

- $\mathrm{CHA}_{2} \mathrm{DS}_{2} \mathrm{VASc}=0 \rightarrow$ ibrutinib without concomitant therapy

- $\mathrm{CHA}_{2} \mathrm{DS}_{2} \mathrm{VASc}=1$ (men) or 2 (women $) \rightarrow$ consider anticoagulant therapy

- $\mathrm{CHA}_{2} \mathrm{DS}_{2} \mathrm{VASc}=2$ (men) or $>2$ (men and women) $\rightarrow$ ibrutinib + anticoagulant therapy

- $\mathrm{CHA}_{2} \mathrm{DS}_{2}$ VASc $\geq 2$ and $\mathrm{HASBLED}>3$ or previous mayor hemorrhagic event $\rightarrow$

consider left atrial appendage closure

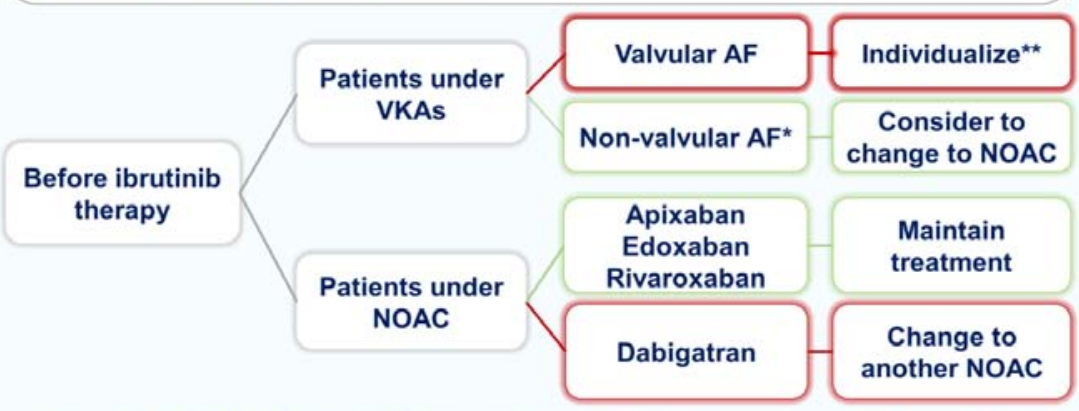

- Non-valvular AF refers to AF in the absence of a mechanical prosthetic heart valve or moderate/severe mitral stenosis (usually of

rheumatic origin)

* Consider keeping VKAs (in patients with stable INR control) vs low molecular weight heparin

Figure 3: Anticoagulant treatment in patients with atrial fibrillation on ibrutinib therapy.

AF: Atrial Fibrillation; VKAs: Vitamin K Antagonists; NOAC: Non-Vitamin K Antagonist Oral Anticoagulants

Table 1: Cardiovascular and non-cardiovascular conditions independently associated with atrial fibrillation [7]

\section{$\mathrm{CV}$ and non-CV conditions associated with atrial fibrillation}

\begin{tabular}{|c|c|}
\hline $\begin{array}{ll}\text { - } & \text { Genetics } \\
\text { - } & \text { Age }>65\end{array}$ & $\begin{array}{ll}- & \text { Heart Failure } \\
- & \text { Valvular Heart disease }\end{array}$ \\
\hline - $\quad$ Obesity & - Myocardial ischemia \\
\hline $\begin{array}{ll}\text { - } & \text { Smoking } \\
\text { - } & \text { Alcohol consumption } \\
\text { - } & \text { Vigorous exercise }\end{array}$ & $\begin{array}{ll}\text { - } & \text { Thyroid dysfunction } \\
\text { - } & \text { Chronic obstructive lung disease } \\
\text { - } & \text { Obstructive sleep apnea }\end{array}$ \\
\hline $\begin{array}{ll}- & \text { Hypertension } \\
\text { - } & \text { Diabetes mellitus }\end{array}$ & $\begin{array}{ll}\text { - } & \text { Chronic Kidney disease } \\
\text { - } & \text { Autonomic dysfunction }\end{array}$ \\
\hline
\end{tabular}

receiving ibrutinib $[8,17]$.

\section{Atrial fibrillation and ibrutinib: management strategies}

A high risk for AF development or prior history of AF should not deter hematologists from considering ibrutinib therapy if indicated. Nevertheless, given the potential lifesaving nature of the drug, a cardio-hematology multidisciplinary approach is desirable to prevent AF events and to improve ibrutinib tolerability [6] (Table 2).

All patients considered for ibrutinib therapy should undergo a detailed evaluation of comorbidities and CV risk, aimed at identifying and correcting baseline AF predisposing factors (Table 1). Patients should also receive a tailored education focused on symptoms recognition, modifiable risk factors for $\mathrm{AF}$, the importance of therapy adherence and the risk of drug-drug interactions (DDI) (Table 2) $[3,4,9,13]$.

Ibrutinib is primarily metabolized in the liver, by cytochrome P450 enzyme 3A4 (CYP3A4), which increases the potential for DDI; therefore, being aware of all the medications that the patient receives during ibrutinib therapy is mandatory (Table 2) [20]. Concomitant use of ibrutinib with strong CYP3A4 inhibitors/inducers should be avoided whenever possible. Strong CYP3A4 inducers have the potential to significantly decrease ibrutinib efficacy whereas strong/ moderate CYP3A4 inhibitors increase the potential of toxicity. If a decision is made to co-administer these drugs, patients should be monitored closely and ibrutinib dose should be adjusted (Figure 1) $[6,20]$. Moreover, patients should be cautioned against using nonsteroidal anti-inflammatory drugs, grapefruit juice, fish oils and vitamin $\mathrm{E}$ during ibrutinib therapy to avoid an increase in the risk of bleeding $[6,20]$.

Due to both the increased risk of hypertension under ibrutinib therapy (incidence of 14-23\%) [21,22] and the increased risk of AF, stroke and bleeding in hypertensive patients [9], a close monitoring of blood pressure is mandatory (Table 2). Baseline electrocardiogram (ECG) should be performed to identify symptomatic/asymptomatic AF, other arrhythmias or ECG abnormalities. Baseline echocardiography may help to optimize CV therapy, especially in patients with new cardiac symptoms, unknown ECG abnormalities and previous CV risk factors [9]. In addition, patients with echocardiographic predictors for AF like left ventricular hypertrophy, moderate to severe dilated left atrium, significant valvular heart disease or left ventricular dysfunction, a more close follow-up should be recommended during the first months of therapy (Table 2) [23].

In patients with a pre-existing AF who need ibrutinib therapy, a cardiology consultation is encouraged to optimize cardiac treatment and review the need for antiplatelet (APT) and/or anticoagulant drugs (Table 2). Based on current AF clinical guidelines, in patients with paroxysmal AF, treated with antiarrhythmic drugs, a rhythm control strategy is preferred, while rate control therapy is the favored option in persistent/permanent $\mathrm{AF}$ and when there is a high risk of recurrence in paroxysmal AF (Figure $2 \mathrm{~A}$ ) $[3,4,9]$.

CYP3A4 inhibitors like diltiazem and verapamil should be avoided and amiodarone or dronedarone used with caution, because they increase ibrutinib levels [20]. If they cannot be avoided, ibrutinib 
Table 2: General rules to guide cardiovascular consultation in patients treated with ibrutinib.

\begin{tabular}{|c|c|c|c|c|}
\hline \multirow{3}{*}{$\begin{array}{ll} & \text { General rules } \\
& \\
\text { - } & \text { Healthy lifestyle } \\
\text { - } & \text { Tailored patient education } \\
\text { - } & \text { Minimize APT } \\
\text { - } & \text { Estimate stroke risk based } \\
\text { on } \mathrm{CHA}_{2} \mathrm{DS}_{2} \text { VASc score } \\
\text { Estimate bleeding risk } \\
\text { based on HASBLED score }\end{array}$} & $\begin{array}{l}\text { Prior to } \\
\text { ibrutinib therapy }\end{array}$ & & \multicolumn{2}{|c|}{$\begin{array}{l}\text { Optimize CV risk factors control and CV diseases treatment } \\
\text { Identify and treat AF predisposing factors } \\
\text { Baseline ECG } \\
\text { Baseline transthoracic echocardiography in patients with previous CV diseases or } \\
\text { abnormal ECG to help further management }\end{array}$} \\
\hline & $\begin{array}{l}\text { CV monitoring } \\
\text { under ibrutinib }\end{array}$ & & $\begin{array}{l}\text { Patients' treatment should be reviewed on a regular basis to } \\
\text { avoid DDI and to optimize blood pressure control } \\
\text { Blood pressure goals } \leq 130 / 80 \mathrm{mmHg} \\
\text { Regular ECG monitoring } \\
\text { Identify and treat AF predisposing factors }\end{array}$ & \multirow{2}{*}{$\begin{array}{l}\text { Avoid ibrutinib } \\
\text { treatment } \\
\text { interruptions in } \\
\text { stable patients }\end{array}$} \\
\hline & $\begin{array}{l}\text { Treatment of ibrutinib } \\
\text { induced atrial fibrillation }\end{array}$ & & $\begin{array}{l}\text { Review reversible AF precipitant factors } \\
\text { Prioritize symptoms and rate control therapy } \\
\text { Reduce modifiable bleeding risk factors } \\
\text { If anticoagulation is indicated prioritize direct factor } \mathrm{Xa} \\
\text { inhibitors over VKAs or dabigatran }\end{array}$ & \\
\hline
\end{tabular}

AF: Atrial Fibrillation; DDI: Drug-Drug Interactions; APT: Antiplatelet Therapy; CV: Cardiovascular; ECG: Electrocardiogram; VKAs: Vitamin K Antagonist

dose should be reduced (Figure 1). There is no DDI with betablockers, flecainide, propafenone or vernakalant. Ibrutinib is also a potent $\mathrm{P}$-glycoprotein (P-gp) inhibitor, and therefore caution is required when administered together with substrates of $\mathrm{P}$-gp with a narrow therapeutic margin. As an example, digoxin should be taken at least 6 hours before or after ibrutinib [20].

In patients who develop A Funder ibrutinib therapy, a priority cardiac consultation is warranted to decide the best AF treatment strategy and consider the need for anticoagulation based on a risk/ benefit analysis. In hemodynamically unstable patients, urgent electrical cardioversion should be considered (Figure 2B) [9]. It is well known that patients who develop ibrutinib-related AF have similar progression-free survival that those who did not, nevertheless withholding treatment or having extended interruptions has been shown to be detrimental to patients' outcomes $[6,8,24]$. For this reason, it is highly encouraged to avoid ibrutinib therapy interruptions in hemodynamically stable patients [7]. The majority of patients are usually treated with a heart rate control strategy, given that a rhythm control strategy has a limited success during ibrutinib therapy, particularly in patients with several comorbidities and AF risk factors (Figure 2B) $[4,6,16]$.

Besides $\mathrm{AF}$ and related complications, bleeding risk under ibrutinib therapy renders anticoagulation therapy for AF challenging. In addition to irreversibly inhibiting BTK, ibrutinib inhibits several other intracellular molecules involved in platelet signaling, including TEC. Thrombocytopenia has been reported in $2-13 \%$ of patients and major bleeding in $1-9 \%$, depending on the age, comorbidities and concomitant anticoagulant or antiplatelet therapy (APT) [6,25].

In the absence of specific scores for cancer patients, current cardio-oncology documents recommend guiding stroke prevention therapy using the $\mathrm{CHA}_{2} \mathrm{DS}_{2}-\mathrm{VASc}$ and the HAS-BLED scores $[3,4,9,26]$. Nowadays APT is not considered as a strategy to reduce AF-related thromboembolic risk [9]. If necessary (e.g., in coronary artery disease patients), aspirin can continue to be used under close monitoring, unless major bleeding is detected [6]. If a short course of "dual" antiplatelet therapy (DAPT) is indicated, ibrutinib would be temporarily withheld. Given the antiplatelet nature of ibrutinib, if long-term DAPT is considered, alternative treatment options should be explored [6].

The use of vitamin $\mathrm{K}$ antagonists (VKAs) is not recommended because patients undergoing these treatments were excluded from the phase II and III studies that led to the regulatory approval of ibrutinib $[21,22]$. Although it is still a matter of strong debate, in patients already on VKAs, continuation of these drugs could be a reasonable option if patients have stable INRs levels or a valvular AF [9,25]. Nonvitamin $\mathrm{K}$ antagonist oral anticoagulants (NOACs) are currently an attractive option $[25,26]$. Currently there is not a direct clinical evidence to demonstrate which NOAC should be preferred, and, therefore, careful consideration for multiple DDI and co-morbidities must be considered in every patient $[6,25,26]$ (Figure 3 ). The main concern is effect ofibrutinib on NOACs' elimination via P-gp inhibition. Dabigatran has been considered the least favored agent because its prodrug, dabigatran etexilate, is a substrate for P-gp. Coadministration of ibrutinib has been shown to affect the elimination of the prodrug and can increase dabigatranplasma levels. Apixaban, rivaroxaban or edoxaban are viable options and no clinically significant interactions have hitherto been reported [20,24-26].

\section{Conclusion}

Ibrutinib, has proven to be highly effective in patients with LCC and related B-cell malignancies; however it is not always optimally administered in clinical practice due to a growing concern of the management of $\mathrm{AF}$ and bleeding risk. It is well know that patients who develop ibrutinib-related AF have similar progression-free survival that those who do not. Conversely, treatment interruptions have a direct negative effect on patient outcomes. Consequently, a multidisciplinary approach including cardiologists and hematologists should be considered to prevent $\mathrm{CV}$ events, and to increase ibrutinib treatment adherence.

\section{References}

1. Chang HM, Moudgil R, Scarabelli T, Okwuosa TM, Yeh ETH. Cardiovascular Complications of Cancer Therapy Best Practices in Diagnosis, Prevention, and Management: Part 1. J Am Coll Cardiol. 2017; 70: 2536-2551.

2. Chang HM, Okwuosa TM, Scarabelli T, Moudgil R, Yeh ETH. Cardiovascular Complications of Cancer Therapy Best Practices in Diagnosis, Prevention, and Management: Part 2. J Am CollCardiol. 2017; 70: 2552-2565.

3. Zamorano JL, Lancellotti $P$, Rodríguez Muñoz D, Aboyans $\mathrm{V}$, Asteggiano B, Galderisi M, et al. 2016 ESC Position Paper on cancer treatments and cardiovascular toxicity developed under the auspices of the ESC Committee for Practice Guidelines: The Task Force for cancer treatments and cardiovascular toxicity of the European Society of Cardiology (ESC). Eur Heart J. 2016; 37: 2768-2801.

4. López-Fernández T, Martín-García A, Santaballa Beltrán A, Montero Luis A García-Sanz R, Mazón Ramos P, et al. Cardio-Onco-Hematology in Clinical Practice. Position Paper and Recommendations. Rev Esp Cardiol. 2017; 70: 
$474-486$.

5. Barac A, Murtagh G, Carver JR, Chen MH, Freeman AM, Herrmann J, et al. Cardiovascular health of patients with cancer and cancer survivors: a roadmap to the next level. J Am Coll Cardiol. 2015; 65: 2739-2746.

6. Gribben JG, Bosch F, Cymbalista F, Geisier CH, Hillmen P, Moreno C, et al. Optimising outcomes for patients with chronic lymphocytic leukaemia on ibrutinib therapy: European recommendations for clinical practice. $\mathrm{Br} \mathrm{J}$ Haematol. 2018; 180: 666-679.

7. Shanafelt TD, Parikh SA, Noseworthy PA, Goede V, Chaffee KG, Bahlo J, et al. Atrial fibrillation in patients with chronic lymphocytic leukemia (CLL). Leuk Lymphoma. 2017; 58: 1630-1639.

8. Brown JR, Moslehi J, O'Brien S, Ghia P, Hillmen P, Cymbalista F, et al Characterization of atrial fibrillation adverse events reported in ibrutinib randomized controlled registration trials. Haematologica. 2017; 102: 1796 1805.

9. Kirchhof P, Benussi S, Kotecha D, Ahlsson A, Atar D, Casadei B, et al 2016 ESC Guidelines for the management of atrial fibrillation developed in collaboration with EACTS. Eur Heart J. 2016; 37: 2893-2962.

10. Farmakis D, Parissis J, Filippatos G. Insights into onco-cardiology: atrial fibrillation in cancer. J Am Coll Cardiol. 2014; 63: 945-953.

11. Buza V, Rajagopalan B, Curtis AB. Cancer Treatment-Induced Arrhythmias Focus on Chemotherapy and Targeted Therapies. Circ Arrhythm Electrophysiol. 2017; 10: e005443.

12. Mathur P, Paydak H, Thanendrarajan S, van Rhee F. Atrial Fibrillation in Hematologic Malignancies, Especially After Autologous Hematopoietic Stem Cell Transplantation: Review of Risk Factors, Current Management, and Future Directions. Clin Lymphoma Myeloma Leuk. 2016; 16: 70-75.

13. Du X, Dong J, Ma C. Atrial Fibrillation a Preventable Disease? J Am Coll Cardiol 2017; 69: 1968-1982.

14. Thorp BC, Badoux X. Atrial fibrillation as a complication of ibrutinib therapy: clinical features and challenges of management. Leuk Lymphoma.2018; 59: $311-320$

15. Leong DP, Caron F, Hillis C, Duan A, Healey JS, Fraser G, et al. The risk of atrial fibrillation with ibrutinib use: a systematic review and meta-analysis. Blood. 2016; 128: 138-140.

16. Thompson PA, Levy V, Tam CS, Al Nawakil, Goudot FX, Quinquenel A, et al. Atrial fibrillation in CLL patients treated with ibrutinib. An international retrospective study. Br J Haematol. 2016; 175: 462-466.
17. Wiczer TE, Levine LB, Brumbaugh J, Coggins J, Zhai Q, Ruppert AS, et al. Cumulative incidence, risk factors, and management of atrial fibrillation in patients receiving ibrutinib. Blood Adv. 2017; 1: 1739-1748.

18. Gustine JN, Meid K, Dubeau TE, Treon SP, Castillo JJ. Atrial fibrillation associated with ibrutinib in Waldenström macroglobulinemia. Am J Hematol. 2016; 91: E312-3.

19. Lee HJ, Chihara D, Wang M, Mouhayar E, Kim P. Ibrutinib-related atrial fibrillation in patients with mantle cell lymphoma. Leuk Lymphoma. 2016; 57 : 2914-2916.

20. De Zwart L, Snoeys J, De Jong J, Sukbuntherng J, Mannaert E, Monshouwer M. Ibrutinib dosing strategies based on interaction potential of CYP3A4 perpetrators using physiologically based pharmacokinetic modeling. Clin Pharmacol Ther. 2016: 100: 548-557.

21. Burger JA, Tedeschi A, Barr PM, Robak T, Owen C, Ghia P, et al. Ibrutinib as initial therapy for patients with chronic lymphocytic leukemia. N Engl J Med 2015; 373: 2425-2437.

22. Byrd JC, Furman RR, Coutre SE, Burger JA, Blum KA, Coleman M, et al. Three-year follow-up of treatment-naïve and previously treated patients with CLL and SLL receiving single-agent ibrutinib. Blood 2015; 125: 2497-2506.

23. Donal E, Lip GY, Galderisi M, Goette A, Shah D, Marwan M, et al. EACVI/ EHRA Expert Consensus Document on the role ofmulti-modality imagingfor the evaluation of patients with atrial fibrillation. Eur Heart J Cardiovasc Imaging. 2016; 17: 355-383

24. Barr PM, Brown JR, Hillmen P, O’Brien S, Barrientos JC, Reddy NM, et al. Impact of ibrutinib dose adherence on therapeutic efficacy in patients with previously treated CLL/SLL. Blood. 2017; 129: 2612-2615.

25. Shatzel JJ, Olson SR, Tao DL, McCarty OJT, Danilov AV, DeLoughery TG. Ibrutinib-associated bleeding: pathogenesis, management and risk reduction strategies. J Thromb Haemost. 2017; 15: 835-847.

26. Steffel J, Verhamme P, Potpara TS, Albadalejo P, Antz M, Desteghe L, et al. The 2018 European Heart Rhythm Association Practical Guide on the use of non-vitamin $\mathrm{K}$ antagonist oral anticoagulants in patients with atrial fibrillation: executive summary. Europace. 2018.
Ann Hematol Oncol - Volume 5 Issue 4 - 2018

ISSN : 2375-7965 | www.austinpublishinggroup.com

López-Fernández et al. (C) All rights are reserved
Citation: López-Fernández T, Canales M, Farmakis D, García-Sanz R, Bosch F, Loscertales J, et al. IbrutinibAssociated Atrial Fibrillation: A Practical Approach. Ann Hematol Oncol. 2018; 5(4): 1203. 